Article

\title{
Evaluating Spatial Disparity of Access to Public Parks in Gated and Open Communities with an Improved G2SFCA Model
}

\author{
Jinguang Zhang ${ }^{1,2}\left(\mathbb{D}\right.$, Yingyi Cheng ${ }^{1,2}$, Wei Wei ${ }^{1,2,3}$ and Bing Zhao ${ }^{1, *}$ \\ 1 The College of Landscape Architecture, Nanjing Forestry University, Nanjng 210037, China; \\ zjg@njfu.edu.cn (J.Z.); Yingyichen@njfu.edu.cn (Y.C.); WeiW@njfu.edu.cn (W.W.) \\ 2 Department of Geosciences and Natural Resource Management, University of Copenhagen, \\ Frederiksberg 1958, Denmark \\ 3 The College of Environmental Science, Nanjing XiaoZhuang University, Nanjng 21000, China \\ * Correspondence: zhbnl0118@njfu.edu.cn; Tel.: +86-13605167303
}

Received: 22 September 2019; Accepted: 20 October 2019; Published: 24 October 2019

\begin{abstract}
A major concern of social equity and environmental justice is whether urban green resources are equitably distributed across the compact megacities of China. Many previous studies have evaluated the disparities in park access among various social groups, but few researchers have considered the heterogeneity of the built environment in residential communities. This study revisits an increasingly popular Gaussian-two-step floating catchment area (G2SFCA) model and mainly improves its two core parameters, the comprehensive supply indicator and variable catchment, in order to realistically evaluate park accessibility under different travel modes. We choose Nanjing city, China, as the study case in which to evaluate differences in public park access with respect to gated and open communities using our improved model. Moreover, gated communities have been further divided into three categories, which represent differences in a community's ability to provide daily physical activities, to more deeply explore disparities in public park services. The results show that (1) the spatial accessibility of parks in Nanjing city is not evenly distributed, with communities located north of the Yangtze River having inferior park accessibility; (2) residents who live in open communities are more restricted with regard to access to parks than those in gated communities, although they experience relatively small differences under the walking mode; (3) gated communities with no internal park ("club park") enjoy better public park services; and (4) residents living in 105 open communities and 167 gated communities without a club park can be regarded as the most vulnerable groups based on the lack of park services. The results of this study can provide a scientific basis for policy makers to target specific communities of vulnerable groups for further urban park development.
\end{abstract}

Keywords: environmental justice; gated and open communities; park quality; effective activity areas; variable catchment; physical activity

\section{Introduction}

Urban parks play a crucial role in advancing the ecological and social sustainability of cities by providing a wide range of ecosystem services, such as capturing carbon, improving air quality [1], reducing noise [2], maintaining biodiversity [3], and preventing heat stress [4]. In addition, access to urban parks contributes to urban residents' ability to enjoy a healthy lifestyle by stimulating physical activity and fostering public health. Several studies have shown that living in proximity to parks contributes to lower rates of overweight and obesity [5], cardiovascular disease [6], and even mental health problems [7]. A clear positive relationship exists among urban parks, their use, and well-being [8], 
and urban parks play a significant role in promoting people's well-being. However, these benefits can be enjoyed only when urban parks are easily and reasonably accessible to urban dwellers and have sufficient effective activity area and amenities. In addition, urban parks are often unevenly distributed across cities, which raises issues such as environmental justice. Therefore, accurately assessing park accessibility is important to identify spatial disparities and locations that require intervention.

Access to parks is influenced by many objective factors (also called spatial factors) that can be interpreted on the basis of three main aspects: supply, demand, and the connection between them. Supply may include, but is not limited to park acreage and park quality [9]. Demand refers to population size and structure, such as the presence of children, senior citizens, and racial and religious groups [10]. Regarding the connection among these spatial factors in terms of issues such as geographic barriers, substantial evidence suggests that proximity, the physical road environment, and transport modes [11,12] from residential districts to parks are closely associated with park accessibility [13-15]. In addition, certain subjective aspects (also called nonspatial factors), such as people's awareness of the benefits of park utilization, park ticket prices, and personal preferences, among other psychological factors, are also important.

A growing number of studies have sought to evaluate park accessibility. Talen et al. advocated an approach to evaluating urban spatial patterns that can be termed "place-based" accessibility [16]; this measure serves to characterize a place. The main measurements involved are "container", "coverage", "minimum distance", "travel cost", and "gravity". The "container" measurement methods, which are most widely used in neighborhood-scale environmental justice and social equity-based analyses [17], identify whether a park is located within a certain geographic unit (e.g., a subdistrict or district). Individual movements are restricted by certain geographic boundaries, and a large unit has a higher probability of containing more supply points if park accessibility is calculated in this manner. Rather than measuring a given restricted geographic unit, "coverage" methods, which typically include buffer analysis [18-20], network analysis [21-23], kernel-density estimation [24], and Thiessen polygons [25], count the number of parks within a specific distance. However, this method is regarded as somewhat arbitrary because it does not determine an appropriate service scope and assumes that a park will be equally enjoyed by all residents at demand points within the predefined supply service area. Additional approaches, such as "minimum distance" and "travel cost" approaches, consider the supply points (e.g., parks) outside the service scope. The former approach measures access as the distance to the nearest facility, whereas the latter approach calculates the distance (cost) between an origin and all included destinations (for example, all parks within a city). These "distance-based" approaches ignore distance-decay functions, people's tolerance thresholds, and park diversity. Therefore, owing to its advantages in capturing park diversity (e.g., size) while considering distance-decay effects, a "gravity-based" measurement has been proposed and widely used to study socioeconomic spatial interactions [26].

The aforementioned metrics depend either on the supply source (e.g., buffer analysis) or the demand source (e.g., the minimum-distance approach). However, measuring accessibility involves determining not only the shortest origin-to-destination (OD) distance, but also the attractiveness of the destination (supply) and the condition of the origin (demand). The two-step floating catchment area (2SFCA) method employs principles from gravity-based models to incorporate supply, demand, and distance into its characterization of accessibility. As a dichotomous technique, in contrast to continuous gravity-based models, the 2SFCA method includes several modified methods to model the distance-decay effect, such as Enhanced 2SFCA [27], Gravity 2SFCA [28], Kernel-Density 2SFCA [29], and Gaussian-based 2SFCA (G2SFCA) [30]. Thus, the 2SFCA method is regarded as more accurate than gravity measurement, which tends to assign overly high accessibility scores to areas with low accessibility [31]. The G2SFCA model, which was first used by Dai [30] in the context of healthcare resources, is an attenuated " $\mathrm{S}$ " model in which accessibility is slower with distance-decay speed at the beginning and end and faster in the middle [32]; this model is also properly compatible with the park accessibility decay mode. However, the G2SFCA model still has some imperfections, and its major 
limitations are that (1) supply indicators mainly consider park size [33] and ignore other available indexes that play essential roles in promoting regular physical activity [29]; (2) each catchment area is set at a fixed distance, regardless of park type and attractiveness [34]; and (3) areal unit problem effects, which assume that all people within the geographic boundary (i.e., district or subdistrict) enjoy uniform access, can hardly be avoided owing to a lack of community-level or individual-level data. Subsequently, Dony et al. developed a variable-width floating catchment area (VFCA) method to address the fixed catchment problem, by incorporating catchment areas of varying sizes [34]. Xing et al. used a multimodal method to evaluate spatial disparities in park accessibility, assuming that residents' travel mode choice was based on having multiple transportation options to solve the fixed catchment problem [35]. To date, little attention has been devoted to a comprehensive supply indicator, thus causing integration of park quality and attractiveness indicators, especially those that are easily available and quantifiable, to be neglected.

With respect to spatial disparities and social inequities related to park accessibility, many previous studies have considered disparities among various social groups [17], such as those defined by socioeconomic status, ethnicity/race, age, and sex, among other factors [29,36,37]. Most of this research has suggested that low-income, ethnic minority people, and disadvantaged groups have fewer opportunities to enjoy park services. However, few studies have considered the heterogeneity of the built environment in residential communities, such as gated communities and open communities. Unlike in Western countries, gated communities, which are surrounded by a wall and are densely developed, dominate the housing market in China: approximately $80 \%$ of greenfield developments and urban renewal projects occur in gated communities owing to the commercial housing reform of 1998 [38], and their proliferation is attributable to many factors, such as social segregation, class filtration, community service, and management. The walls surrounding gated residential areas make walking less desirable and lead to "the deserted sidewalk" phenomenon; on the other hand, these communities have more outdoor infrastructure, more open spaces, and better pedestrian environments within the walls. Almost all open communities are welfare housing neighborhoods or villages within cities that may have higher street connectivity, but inferior living environments. Dong et al. found that people living in gated communities tend to have higher levels of education, income, and automobile ownership than those in open communities [39]. Residents living in open communities can be generally regarded as belonging to socially disadvantaged groups. Therefore, evaluating differential accessibility to public parks between gated and open communities may be a meaningful research area for identifying disparities in park services with regard to "geographical justice".

Inspired by the challenge of evaluating park accessibility with the G2SFCA model and exploring spatial disparities in public park services with regard to the heterogeneity of the built environment in communities, this study selects Nanjing as its case and pursues two objectives. First, it improves two significant issues facing the 2SFCA model to more realistically evaluate park accessibility. These improvements include (1) using a comprehensive indicator to describe the capacity of park supply by integrating park size, effective activity area, tree canopy coverage ratio, and park trail density, which are crucial for attracting and stimulating physical activity; and (2) considering variable catchment sizes in terms of the type of park and travel mode (walking, bicycling, and riding by private car) to solve the fixed catchment limitation. Second, this study evaluates park accessibility at the community level and explores spatial disparities in park accessibility to identify the differences between open communities and gated communities.

\section{Study Area and Data}

\subsection{Study Area}

Nanjing, the capital of Jiangsu Province, has nearly 2000 years of history. It is located in the western Yangtze Delta; the Yangtze River runs through the city, dividing it into two regions, and the Qinhuai River runs southeast-northwest through the city to join the Yangtze River. Nanjing covers 
an area of approximately $6587 \mathrm{~km}^{2}$, and nearly $10 \%$ of the total area is low hills, which are located mainly on the edges of the city core and extend into the built-up areas. The metropolitan region contains eleven districts with a total population of more than 8.3 million. Thus, Nanjing is one of the most rapidly urbanizing and densely developed cities in China. For this case study, we selected a total area of $857 \mathrm{~km}^{2}$ in the inner city, covering 7 whole districts and 2 main districts (in the suburbs), 74 subdistricts, and 1494 communities, and representing the core area of Nanjing. According to the sixth national census, the population of the central urban districts of Nanjing constitutes approximately $75 \%$ of the total population (Figure 1).
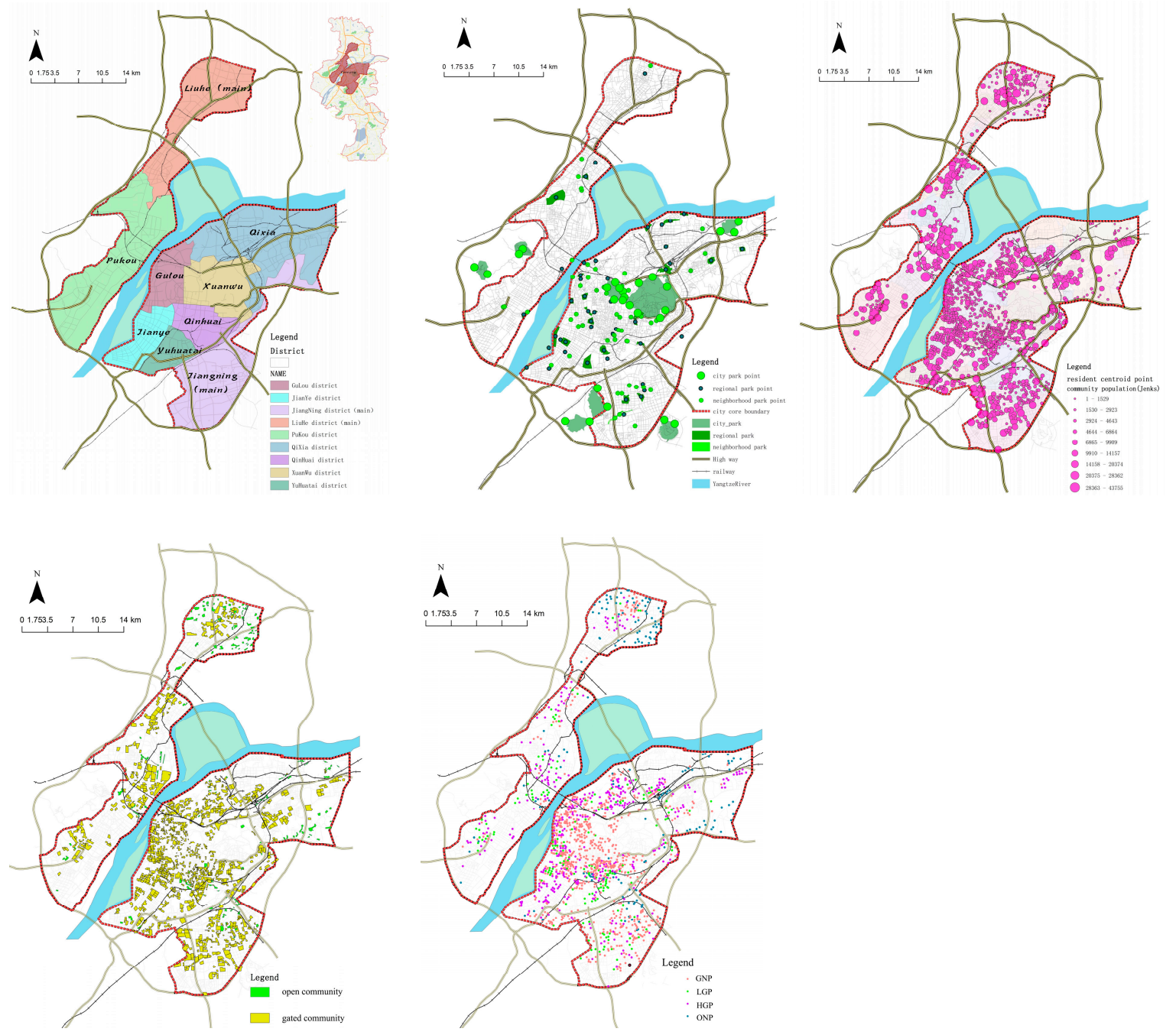

Figure 1. The basic data of the study area-district, park, population distributions (jenks), and community classification.

The quantity and quality of urban parks in Nanjing have increasingly improved over the past decade. The per capita green area of the city compared with those of other cities in the world was $13.38 \mathrm{~m}^{2}$ in 2014, which is far below adequate [40] and does not meet the city's urban planning goal. Because Nanjing is a congested and compact city with meager urban green space, accurately delineating the shortage of park accessibility and enhancing the usage efficiency of urban parks are essential.

\subsection{Data}

Vector data (polygons in shapefile ArcGIS ESRI format) of the locations and sizes of the parks were created based on the Planning of Nanjing City Parks (2017-2035); Green Space System Planning of Nanjing 
City (2010-2020); and satellite images of Nanjing from Google Earth with Bigemap, a high-definition map downloader with a pixel accuracy of $0.25 \mathrm{~m}$ that is updated every 3-6 months in China. On the basis of the Accessible Natural Green Space Standards (ANGSt) [23] and combined with local standards, urban parks in Nanjing were classified into three types by size: small (community/neighborhood level; 2 20 ha), medium (regional level; 20 100 ha), and large (city/metro level; $\geq 100$ ha). City-level parks that surround the study area were considered to avoid the common "edge effect" that may skew accessibility data along the border. After deliberately excluding parks that are small in size (less than 2 ha), have few amenities, and have poor management, 109 available parks were included: 8 city parks, 49 regional parks, and 52 neighborhood parks, covering a total area of approximately $88.26 \mathrm{~km}^{2}$.

The administrative system in mainland China is a seven-tier hierarchy in which district, subdistrict (Jiedao in Chinese), and community (administered by a residential committee) are the dominant spatial statistical units for population census data [41]. China has conducted six national population census surveys since the 1980s; however, the National Bureau of Statistics usually releases official census data at only the district and subdistrict levels. For the community-level population, the shadow-length method [42] was used to determine the number of building floors based on the height of the shadow of residential buildings and to calculate the total living area. According to the Statistical Yearbook of Nanjing 2016, the per capita living area is $36.5 \mathrm{~m}^{2}$. Therefore, dividing the total living area by per capita living area assisted us in estimating the population of each community.

Transportation data, including complete vectorial road network data for 2019, were obtained from Bigemap. In addition, urban road networks were typically classified as highway, major road, secondary road, and branch.

\subsection{Classification of Communities}

A total of 1497 residential communities exist in the Nanjing city core, which have different spatial patterns with respect to factors such as population density and the living built environment. To explore the disparities in public park access across different types of residential communities, we divided communities into four categories. First, open communities and gated communities were distinguished depending on whether a wall surrounded residential quarters. Open communities have less outdoor infrastructure, less open space, and worse living environments than gated communities; thus, they are considered to be the groups most in need of public parks for daily physical activities. Second, almost $89 \%$ of communities in the core city of Nanjing are gated communities, which were further classified into three categories based on the floor heights of the community dwellings and the availability of internal community parks ("club parks"):

1. gated community with no internal community park; such communities are almost exclusively low-rise dwellings, as high-rise dwellings are mainly newly built communities that are equipped with a club park;

2. gated community with a low population density (low-rise dwellings) with an internal club park; such internal parks can meet the fundamental demand of daily recreation;

3. gated community with a high population density (high-rise dwellings) and an internal community park; such parks may serve as a substitute for a public park [43], but the large resident population may indicate that the available green space resources are inadequate.

In sum, we divided communities into four levels of public parks from the spatial heterogeneity perspective, representing the communities' ability to facilitate residents' engagement in fundamental daily physical activities and meet their requirements for public parks. The following community types are sorted based on the required public park level(Figure 2): an open community with no park (ONP), a gated community with no internal park (GNP), a high-population-density gated community with an internal park (HGP), and a low-population-density gated community with an internal park (LGP). 

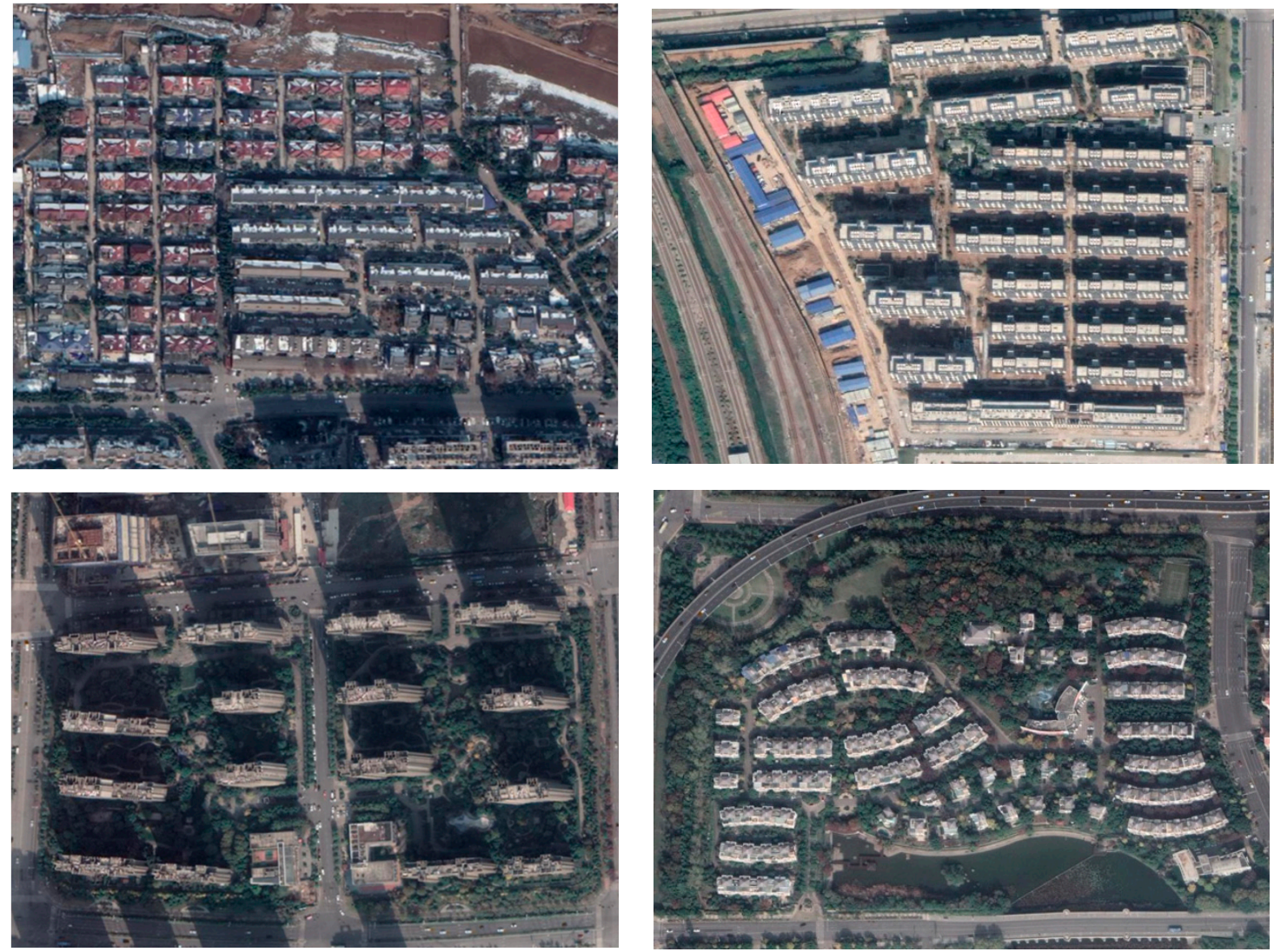

Figure 2. Four typical communities: ONG, GNP, HGP, LGP. ONP, open community with no park; GNP, gated community with no internal park; HGP, high-population-density gated community with an internal park; LGP, low-population-density gated community with an internal park.

\section{Methods}

\subsection{Gaussian-Based 2SFCA Model}

The G2SFCA model, which was first proposed by Dai [30] and later used by many researchers to evaluate park accessibility [33-35,44,45], is an extension of the traditional model [31] that modifies the distance-decay function based on a threshold travel time. The method is implemented using a two-step procedure. First, the overall demand location $i$ is determined within a threshold travel time $t_{0}$ for each park $j$. Then, the populations at $k$ are weighted using a Gaussian function $(G)$ and summarized to compute the service-to-population ratio $R_{j}$ :

$$
R_{j}=\frac{S_{j}}{\sum_{k \in\left\{d_{k j} \leq d_{0}\right\}} G\left(d_{k j}, d_{0}\right) P_{k}},
$$

where $P_{k}$ is the population at location $k$ with its centroid in the catchment (i.e., $d_{k j} \leq d_{0}$ ) from park location $j ; d_{k j}$ is the distance between population location $k$ and park location $j ; S_{j}$ is the capacity of the park at $j$; and $G$ is the friction of distance, as follows:




Next, the overall park locations within $t_{0}$ are searched for each demand population $i$, and the service-to-population ratio $R_{j}$ is summed to calculate spatial accessibility $A_{i}$ at demand location $i$ :

$$
A_{i}=\sum_{l \in\left\{d_{i} \leq d_{0}\right\}} G\left(d_{i l}, d_{0}\right) R_{l}
$$

where $l$ represents all parks within the catchment of population $d$ at location $i$. The accessibility score $A_{i}$ suggests the park service capacity per capita.

\subsection{Improved Model Parameters}

Spatial proximity to a park is a primary factor influencing park access, because those who live near parks are more likely to achieve the recommended levels of physical activity [46]. Park quality is another critical aspect of the equitable distribution of park resources in urban areas, although it has received less attention than the spatial distribution of park resources. Inspired by these factors, we aim to improve two parameters $\left(S_{j}\right.$ and $\left.d_{0}\right)$ of the G2SFCA method to realistically estimate the spatial accessibility of urban parks. First, the attraction coefficient $S_{j}$ (referring to park quality) in the first step is enhanced using a comprehensive index that integrates certain objective indicators that are crucial for attracting residents and promoting physical activity. Second, the fixed threshold $d_{0}$ (referring to park proximity) is modified by using different cut-off values to represent variable catchment sizes in terms of the type of park and residents' travel modes.

\subsubsection{Enhanced Coefficient $S_{j}$}

The coefficient $S_{j}$ represents the capacity of urban parks and refers to a park's quality and attractiveness. Most equity studies on urban parks have used the 2SFCA method to calculate accessibility by summing the attraction coefficient $S_{j}$, which considers only park sizes in the first step [35]. In addition to determining the size of green spaces, an environmental audit of factors such as tree coverage, picnic areas, accessible water bodies, and benches is necessary to describe urban parks. However, few studies have focused on these indexes and have applied them to the 2SFCA model. One problem is quantitatively defining and integrating the quality of urban parks. In this study, we present a new index called the "effective activity area", indicating that visitors can freely enter the activity areas of a park (including playgrounds, grassy areas, water bodies, and woodlands but not park roads) that represent potential opportunities for more amenities and recreational facilities. In addition, according to the Code for the Design of Public Parks (CDPP) (GB51192-2016) of China, two additional crucial indicators-tree canopy coverage and park trail density-are taken into account. The former indicator is regarded as the basic standard for measuring the quality of urban parks, which varies depending on the park size (e.g., an $80 \%$ tree canopy coverage ratio is the specified value for city-level parks greater than 100 ha in size). The tree canopy can also promote physical activity, as it provides shade for playgrounds in the summer [47]. The latter indicator represents the ratio of park trail length to park area, which has an optimal interval value. If the value is too high, then the park traffic will be chaotic, whereas if it is too low, visitors will be unable to efficiently reach every scenic spot of the park, thus reducing opportunities for walking activity [13]. Notably, the four abovementioned indexes can be easily inspected using satellite imagery, geographic information systems, and remote sensing technology. Finally, the AHP-entropy method is used to integrate park size, effective activity area, tree canopy coverage ratio, and park trail density, instead of only a park size-based indicator.

The AHP-entropy approach is a combination of AHP and the entropy method [48]. Following are five steps of determining the weights of factors' significance from the stage of factor values assessment (standardization): 
(1) AHP weights designated by experts

AHP is a system analysis method that uses a combination of qualitative and quantitative analyses. This method considers the knowledge and experience of experts and the intentions and preferences of decision-makers to determine the index weight sorting, which has a higher rationality, but much greater discretionary subjectivity than other sorting methods. The AHP weights were determined with the help of urban park planning experts, including Chinese planners, university faculty members, and doctoral students in planning and land administration departments. We selected the experts based on their experience with green space planning and sent survey forms to a total of 30 experts, 8 of whom are faculty members in departments of planning and land administration, while 10 are planners and professionals, and 12 are doctoral students in landscape architecture and urban planning. We assigned different weights to the indexes in terms of the AHP method: park size (0.31), effective activity area (0.26), tree canopy coverage ratio $(0.24)$, and park trail density $(0.19)$.

(2) Standardization of indicators' values of entropy method

The entropy method is an objective weighting method, and the determination of the indicator weights depends mainly on the impact of the relative degree of change in the index. However, this method considers only the benefit indicator (the larger the better) or the cost indicator (the smaller the better). Park size, effective activity area, and tree canopy coverage ratio are benefit indexes, while trail density is an interval indicator (the closer the indicator is distributed to the optimal interval, the better) (Figure 3). Therefore, we preprocessed the park trail density indicator as follows:

$$
b_{i j}=\left\{\begin{array}{cl}
1-\frac{\left(a_{j}^{0}-a_{i j}\right)}{a_{j}^{0}-a_{j}^{n}} & , \text { if } a_{j}^{n} \leq a_{i j}<a_{j}^{0} \\
1 & , \text { if } a_{j}^{0} \leq a_{i j}<a_{j}^{*} \\
1-\frac{\left(a_{i j}-a_{j}^{*}\right)}{a_{j}^{m}-a_{j}^{*}} & , \text { if } a_{j}^{*} \leq a_{i j}<a_{j}^{m}
\end{array}\right.
$$

where $a_{i j}$ and $b_{i j}$ represent the old and new standard park trail density indicators, respectively; $\left[a_{j}^{0}, a_{j}^{*}\right]$ is the optimal interval value, which is $150 \mathrm{~m} / \mathrm{ha}, 380 \mathrm{~m} / \mathrm{ha}$ based on the CDPP; $a_{j}^{n}$ is the minimum of the data; and $a_{j}^{m}$ is the maximum of the data.
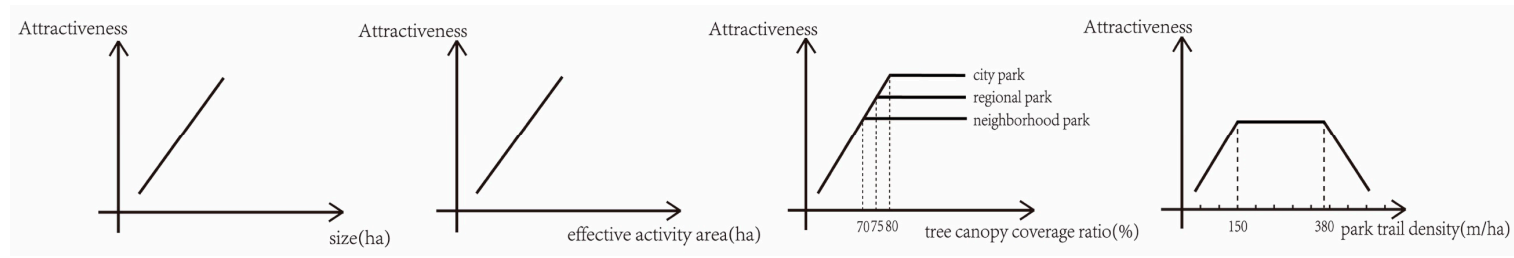

Figure 3. The influence of park attractiveness on physical activity under ideal conditions.

In this study, we assumed that the attractiveness value of a park would remain constant if the tree canopy coverage ratio reached the specified value based on the CDPP. Therefore, the standard tree canopy coverage ratio index can be expressed as follows:

$$
k_{i j}=\left\{\begin{array}{c}
1-\frac{\left(s_{j}^{0}-s_{i j}\right)}{s_{j}^{0}} \\
1, \text { if } s_{i j} \geq s_{j}^{0}
\end{array}, \text { if } s_{i j}<s_{j}^{0},\right.
$$

where $s_{i j}$ and $k_{i j}$ represent the old and new standard tree coverage ratio indicators, respectively, and $s_{j}^{0}$ is a qualified value that varies depending on the size and type of urban parks. According to the 
CDPP, tree canopy coverage ratios of $80 \%, 75 \%$, and $70 \%$ are the specified values for a city-level park, district-level park, and community-level park, respectively.

(3) Weights based on entropy

Then, the entropy method can be typically operated through the following steps:

(1) Establish judgment matrix $D$, composed of $m$ evaluation schemes and $n$ evaluation indexes; $A_{i j}$ is the evaluation index $j$ for park $i$ :

$$
D=\left(A_{i j}\right)_{m \times n^{\prime}}(i=1,2, \ldots, m ; j=1,2, \ldots, n) .
$$

(2) Carry out the standardized processing of matrix $D$ to obtain the nondimensional index matrix, and the evaluation results are all benefit indicators after the preprocessing steps:

$$
r_{i j}=\frac{A_{i j}-\min \left\{A_{i j}\right\}}{\max \left\{A_{i j}\right\}-\min \left\{A_{i j}\right\}} .
$$

(3) Calculate the proportion of park $i$ under index $j$ :

$$
P_{i j}=\frac{A_{i j}}{\sum_{i=1}^{n} A_{i j}} .
$$

(4) Calculate the entropy value of the $j$ th evaluation indicator $E_{j}$ and the entropy weight $\mu_{j}$ :

$$
E_{j}=-\frac{1}{\ln (n)} \sum_{j=1}^{n} P_{i j} \ln \left(P_{i j}\right),(j=1,2, \ldots, n) ; \mu_{j}=\frac{1-E_{j}}{n-\sum_{j=1}^{n} E_{j}} .
$$

(4) Final weights

Use the index weights $\mu_{j}$ determined by the aforementioned entropy weight method to revise the weights $\lambda_{j}$ of each indicator determined by AHP. The final weight of the $j$ th evaluation index is as follows:

$$
\omega_{j}=\frac{\mu_{j} \lambda_{j}}{\sum_{j}^{n} \mu_{j} \lambda_{j}} .
$$

Finally, the final weight is calculated based on the AHP-entropy method: park size (0.43), effective activity area (0.26), tree canopy coverage ratio $(0.14)$, and park trail density $(0.17)$.

(5) Modified $S_{j}$-weighted linear combination

Therefore, we can calculate a comprehensive score for every urban park with the following equation and redistribute all $S_{j}$ values between 0 and 10 . The score has no practical meaning, but represents the service capacity of urban parks (the higher the better):

$$
S_{j}=\sum_{j=1}^{n} p_{i j} * \omega_{j}(i=1,2,3,4 \ldots m) .
$$

\subsubsection{Variable Threshold $d_{0}$}

Another major limitation of the G2SFCA model is that each catchment area is preset at a fixed distance, regardless of the type and attractiveness of the park. This approach does not align with the actual situation of park planning. Thus, predefining the threshold $\left(d_{0}\right)$ is crucial because it determines the catchment size used to calculate park accessibility. Instead of the fixed value, we present the 
variable threshold $d_{0}$, which is modified by using different cut-off values to represent the variable maximum acceptable distance (or time) in terms of the type of park and residents' travel modes.

Standards documenting the tolerance threshold are increasingly being developed in the literature. The Accessible Natural Greenspace Standard (ANGSt) determined that people should have access to at least one natural green space of 2 ha within $300 \mathrm{~m}$, a 20 ha site within $2 \mathrm{~km}$, and a 100 ha site within $5 \mathrm{~km}$ [23]. The National Recreation and Parks Association, along with the Trust for Public Land and the Congress for New Urbanism, has advocated that all urban residents should have parks within $400 \mathrm{~m}$ [49]. Xu et al. presented tolerance thresholds for visiting parks in Shenzhen, China, as follows: < $18 \mathrm{~min}$ (bicycling), $<15 \mathrm{~min}$ (driving in a private car), and $<30 \mathrm{~min}$ (walking) [36]. Xing et al. found in a survey that people in Wuhan, China prefer to walk $20 \mathrm{~min}$ to parks for exercise and to drive $30 \mathrm{~min}$ to parks for recreation [35]. Planning of Nanjing City Parks (2017-2035) recommends that people have access to a community-level park within a $10 \mathrm{~min}$ walk and to a district-level park within a 20 min walk.

Combining local normative standards, online surveys, and previous research $[35,36]$, we present variable maximum acceptable times depending on the type of park and residents' travel modes(Table 1). Residents generally choose to walk and bicycle to neighborhood parks and take buses and cars to city parks in Nanjing.

Table 1. Variable maximum acceptable times.

\begin{tabular}{cccc}
\hline Travel Mode & Neighborhood Park & Regional Park & City Park \\
\hline Walking & $10 \mathrm{~min}$ & $20 \mathrm{~min}$ & $30 \mathrm{~min}$ \\
Bicycling & $5 \mathrm{~min}$ & $18 \mathrm{~min}$ & $45 \mathrm{~min}$ \\
Driving & - & $15 \mathrm{~min}$ & $30 \mathrm{~min}$ \\
\hline
\end{tabular}

Therefore, the variable threshold $d_{0}$ can be expressed as $d_{0}=t_{i} \times v_{j}$, where $i$ is the type of park; $j$ is the travel mode; $t$ represents the residents' maximum acceptable travel time; and $v$ is travel speed, with walking speed determined to be $4 \mathrm{~km} / \mathrm{h}$ and biking speed to be $10 \mathrm{~km} / \mathrm{h}$. Driving speed is variable depending on road speed limits: highway, $100 \mathrm{~km} / \mathrm{h}$; major road, $50 \mathrm{~km} / \mathrm{h}$; secondary road, $40 \mathrm{~km} / \mathrm{h}$; and branch road, $30 \mathrm{~km} / \mathrm{h}$.

To implement the improved 2SFCA model, the supply and demand point data of the study area were inputted, and travel time was calculated using the network distance based on the actual roads in the network. The analysis module of the ArcGIS 10.5 platform was used instead of the Euclidean distance, the latter of which overestimates park accessibility because it considers only straight-line distances [45]. For supply points, geometric centroids of neighborhood parks and regional parks were utilized to represent the parks. In addition, parks with an irregular shape, such as linear parks, were divided into regular shapes to identify the centroids. For city-level parks that are gated and cannot be easily accessed at all points, the points of the actual entrances were selected. For demand points, population-weighted centroids are a more reasonable reflection of the demands of urban residents than geographic centroids because of the uneven distribution of the population [44]. Therefore, we can calculate the park accessibility scores of each community under different traffic modes (walking, bicycling, and driving) and use the inverse distance weighted (IDW) spatial interpolation method for visualization of the distribution [50].

\section{Results}

\subsection{Park Accessibility at the Community Level}

The community level is the smallest residential and administrative unit in Chinese cities [41]. The accessibility scores of communities with different travel modes and different park types are analyzed to explore disparities in accessibility in detail. In terms of travel mode, walking access to neighborhood parks, regional parks, and city parks is very poor. In addition, bicycling access to city parks is not ideal, but regional parks are more easily reached. In contrast, driving access to city parks is overwhelmingly 
favorable. With regard to the spatial distribution of park accessibility scores, the communities with high park accessibility scores are located mainly in the areas surrounding Zijin Mountain Park and XuanWu Lake Park in the center, QiXia Mountain Park in the east, and Niushou Mountain Park in the south, leaving the areas located along the Yangtze River with poor spatial access. The low score of the Yangtze River area is mainly because of the freight function of the Yangtze River, which has resulted in a large number of factories near the river and unfavorable connections within the city core. Owing to urban sprawl, the number of people living in this area has gradually increased, and few undeveloped land areas remain for the new construction of green spaces, thus resulting in a shortage of supply. In addition, the inhabitants of all residential areas that were distributed north of the Yangtze River cannot access a city park by walking or cycling within the maximum acceptable time, indicating that the inhabitants of these areas can barely enjoy city park services. This finding conveys the urgent need for more city-level parks in the areas north of the Yangtze River. Moreover, the accessibility scores of urban peripheral areas gradually increase as the range of transit options increases (i.e., being able to walk, bike, or drive to a park increases its accessibility). Owing to the "edge effect" and the fact that many parks are located in suburbs, the accessibility scores along the western and southern borders increase with changes in travel modes and increases in the available catchment area (Figure 4).
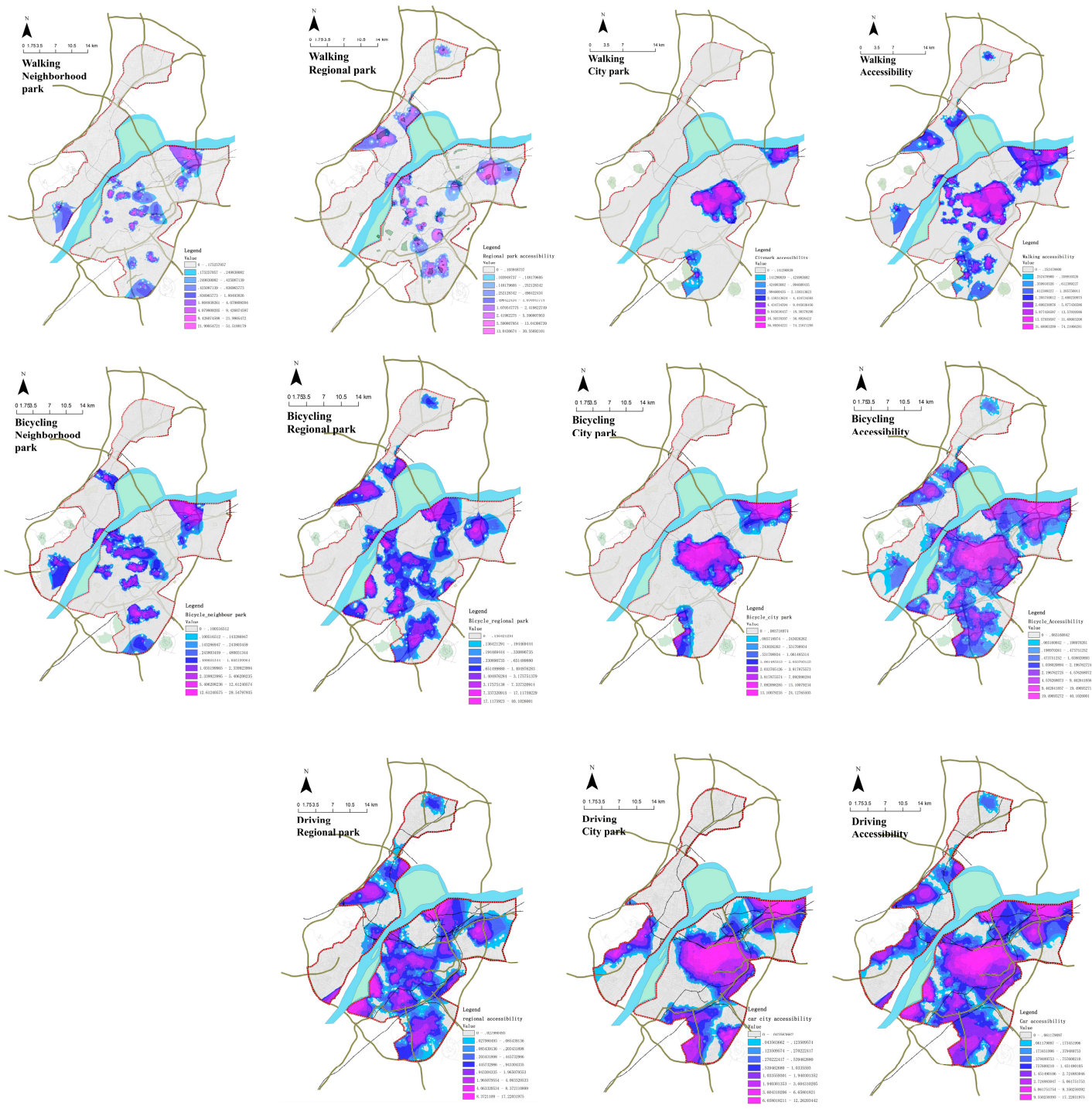

Figure 4. Park accessibility at the community level under different travel modes. 
According to the statistical analysis (Figure 5), 484 communities have a park accessibility score of zero, accounting for $32.3 \%$ of the total number of communities. Residents living in these residential areas cannot enjoy the services of public parks by walking, bicycling, or driving within the acceptable time limit. The inhabitants of $16.2 \%$ of the residential communities can visit regional or city parks only by driving. Moreover, only 210 communities, or $14.0 \%$ of the total, can access parks by walking, indicating that areas with relatively lower walking accessibility constitute a considerable proportion of the total.

Meanwhile, the median, mean, and standard deviation values of the park accessibility scores were calculated at the community level under the three transit modes: walking $(0.00,1.30$, and 5.80, respectively), bicycling $(0.90,1.82$, and 3.81 , respectively), and driving $(0.63,1.58$, and 2.45 , respectively). The results suggest that the mean and median values of walking accessibility are the smallest, while its standard deviation is the largest across the modes, indicating that the walking accessibility of urban parks is relatively poor and that the disparity in walking accessibility is the greatest among the three traffic modes. Therefore, the local government should focus on improving the efficiency of walking to parks by constructing new green space corridors, such as roadside parks and riverside parks.

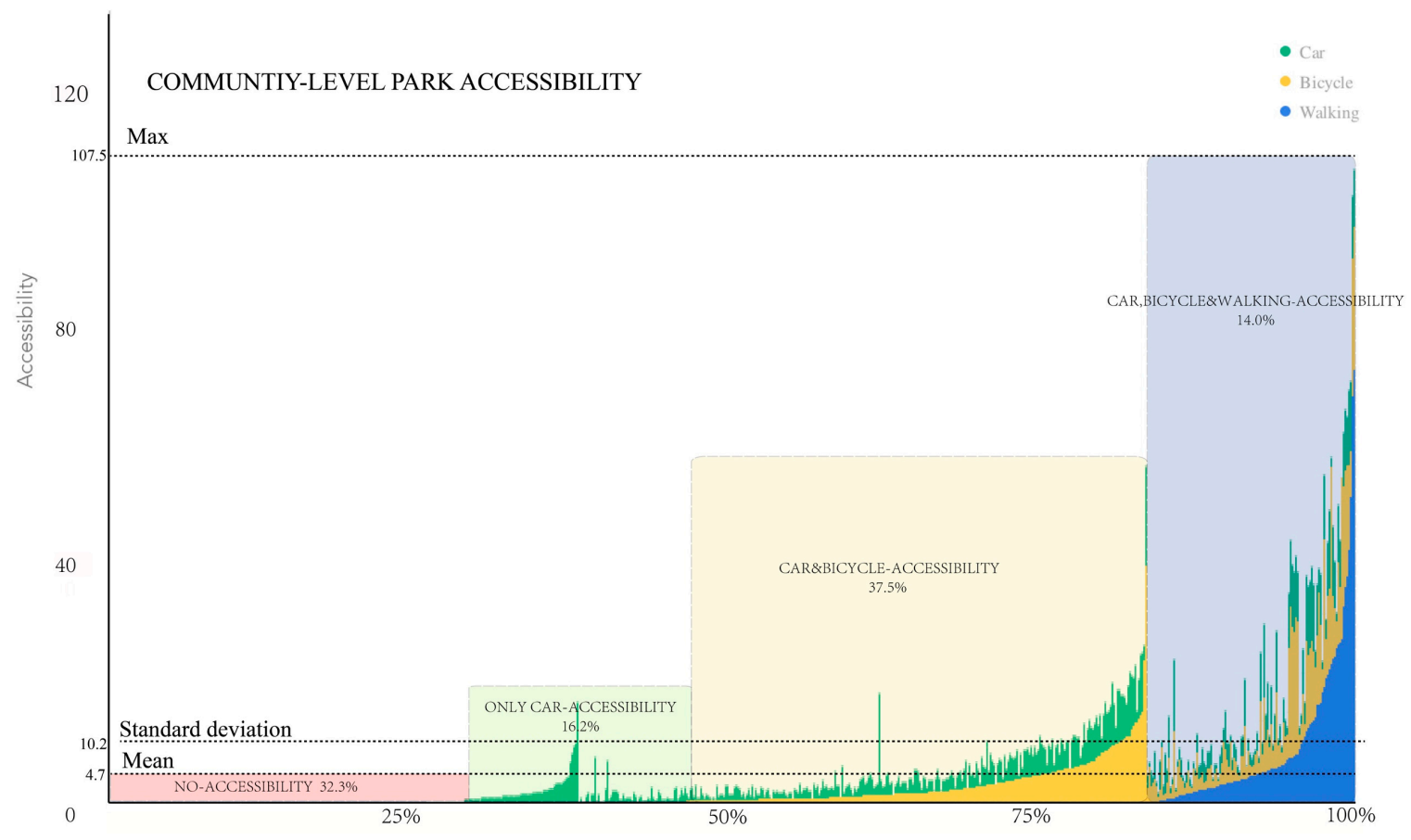

Figure 5. Statistical comparisons of park accessibility at the community level.

\subsection{Disparities in Park Accessibility between Gated and Open Communities}

The mean accessibility score of gated communities is higher than that of open communities, which indicates that residents living in gated communities have more opportunities to enjoy urban park services (Table 2). However, the standard deviation of gated communities is also higher than that of open communities, which suggests that disparities in access to parks are more evident for gated communities than for open communities. According to travel mode, bicycling accessibility for gated communities has the highest mean score, indicating that people living in gated communities have easier access to parks via cycling. Conversely, driving to parks from open communities has the lowest score, suggesting restrictions in park accessibility for people living in open communities seeking to visit parks by private car. The maximum score is found for walking accessibility for gated communities, indicating that people living in gated communities have optimal park accessibility under the walking mode. The minimum values are all 0 , suggesting that regardless of whether people live in gated or open communities and regardless of their preferred mode of travel, some residents still cannot 
access public parks within acceptable time limits. Moreover, when comparing the mean values of park accessibility between gated and open communities, walking accessibility shows the smallest differences. Despite the poor walking accessibility of the open communities, the disparities that they experience are relatively small because of the better road network connectivity of open communities.

Table 2. Descriptive statistical analysis of park accessibility in open and gated communities.

\begin{tabular}{cccccc}
\hline Community Type & Travel Mode & Mean & Min & Max & SD \\
\hline \multirow{4}{*}{ Open community } & Walking & 0.91 & 0.00 & 26.93 & 4.45 \\
& Bicycling & 1.39 & 0.00 & 33.84 & 4.24 \\
& Driving & 0.81 & 0.00 & 10.15 & 2.00 \\
& Total & 3.12 & 0.00 & 59.05 & 9.17 \\
& Walking & 1.36 & 0.00 & 74.35 & 5.94 \\
Gated community & Bicycling & 1.87 & 0.00 & 40.39 & 3.75 \\
& Driving & 1.67 & 0.00 & 17.24 & 2.49 \\
& Total & 4.90 & 0.00 & 107.57 & 10.30 \\
\hline
\end{tabular}

Among gated communities, GNPs, which were built in the early years of implementing commercialization of the housing market, have the highest score for park accessibility, suggesting that inhabitants living in gated communities without internal club parks may enjoy better public park services. Because the allocation of urban parks is primarily based on the availability of natural resources, those communities built in the early years occupied a better natural resource position in Nanjing city. Nevertheless, the standard deviation for the GNP group is also the highest in these areas, indicating that their disparities in urban park accessibility are the greatest. However, the inhabitants living in HGPs and LGPs have fewer opportunities to access parks than those living in GNPs. Although their internal club parks, which are provided by homeowner associations and private management companies [43], may not meet all fundamental physical activity demands, they can relieve pressure on city parks to a certain extent. However, the inhabitants of ONPs also have relatively lower values for urban park accessibility and do not have internal parks, suggesting that people living in ONPs have the least opportunity to enjoy park services(Table 3). Consequently, it is alarming that environmental injustice accompanies spatial heterogeneity and housing segregation, and that the present urban green facilities favor specific groups of people.

Table 3. Descriptive statistics of classification in terms of required levels for public parks.

\begin{tabular}{cccccccc}
\hline Required Level & Community Type & Classification & Number & Mean & Min & Max & SD \\
\hline 1 & Open community & ONP & 167 & 2.81 & 0.00 & 59.05 & 8.74 \\
2 & & GNP & 759 & 6.41 & 0.00 & 107.57 & 11.74 \\
3 & Gated community & HGP & 403 & 2.74 & 0.00 & 54.60 & 5.39 \\
4 & & LGP & 165 & 3.60 & 0.00 & 103.05 & 11.50 \\
\hline
\end{tabular}

ONP, open community with no park; GNP, gated community with no internal park; HGP, high-population-density gated community with an internal park; LGP, low-population-density gated community with an internal park.

Bivariate correlations were used to explore the deeper disparities in the accessibility scores among these four types of communities. Table 4 shows the correlations between the required levels of public parks and the accessibility scores under the different travel modes. The results indicate relative equality such that poorer park access is significantly associated with communities with lower required levels of public parks. However, the correlation coefficient is very weak because residents of most open communities, located mainly northwest of the Yangtze River, have less opportunity to enjoy park services. This observation may also be supported by considering the spatial structures of parks and the population distribution, suggesting that GNPs are mostly located in older city areas, which have a large number of more attractive parks (e.g., XuanWu Lake Park and Zijin Mountain Park) and relatively 
small populations; most LGPs and HGPs are located in the renewal area, where urban parks are lacking and the population is relatively large.

Table 4. Bivariate correlations between park demand levels and accessibility scores.

\begin{tabular}{ccccc}
\hline Demand Level (1 4) & Walking & Bicycling & Driving & Total \\
\hline $\begin{array}{c}\text { Spearman's rank } \\
\text { correlation coefficient }\end{array}$ & $-0.058^{*}$ & $-0.071^{* *}$ & $-0.054^{*}$ & $-0.053^{*}$ \\
Significance & 0.024 & 0.006 & 0.035 & 0.04 \\
\hline
\end{tabular}

* Significant at 0.05 level; ** Significant at 0.01 level.

\section{Discussion}

\subsection{Advantages of the Improved 2SFCA Model}

In this study, we adopted the popular G2SFCA model [30], which incorporates the interaction among supply, potential demand, and travel cost, and considers the distance-decay (Gaussian) effect of spatial accessibility. We improved the two core parameters $\left(S_{j}\right.$ and $\left.d_{0}\right)$ to accurately revisit the environmental justice issues associated with disparities in access to public parks.

\subsubsection{Comprehensive Supply Indicator}

Most park accessibility studies on urban parks have used the 2SFCA method to evaluate supply capacity; these studies consider only park sizes [33,44,45,51]. Size is absolutely critical because, compared with a small neighborhood park, a large city park may provide more functions and thus promote more planned physical activity [49]. However, if the large park has fewer activity amenities, insufficient green space, and an unreasonable trail system density, it can hardly attract visitors. Pham et al. proved that engagement in sports and exercise was a predominant factor in explaining the higher frequency and duration of park visits [52]. Dony et al. provided a new perspective for improvement to evaluate the capacity of park services in a more realistic manner. Nine amenities, such as baseball fields and picnic areas, were added as desirable physical activity attractions, and these amenities were recorded in binary terms ( 1 if the amenity was available at a park and 0 otherwise). However, this list is not exhaustive, nor does it reflect the quantity or quality of each amenity [34]. In this study, we present a new index, "effective activity area", to calculate the capacity of supply more accurately. The "effective activity area" indicates that visitors can freely enter the activity areas of a park, including the available playgrounds, grassy areas, water bodies, and woodlands, but not park roads; this type of access provides potential opportunities for more amenities and recreational facilities, and can thus ensure the promotion of recreational and social activities and can especially stimulate physical activities that are strongly associated with better physical health. We also combined the tree canopy coverage ratio and park road density stipulated in the CDPP-a Chinese park design standard that is based on a large number of successful practical cases-to further capture the attractiveness of parks. The AHP-entropy method was used to integrate the park size, effective activity area, tree canopy coverage ratio, and park trail density to form a comprehensive supply indicator.

Meanwhile, we compared the comprehensive supply indicator with the only park size-based value, which is calculated based on the assumption that other indexes are equal to zero(Figure 6). Significant disparities were found after integrating the other three indexes. For example, if the parks are sorted only by size, XuanWu Lake park is the fifth largest park in Nanjing. However, this park ranks second in size when effective activity areas, tree canopy coverage ratio, and park trail density are integrated into the calculation. Owing to its abundant amenities and effective activity areas, XuanWu Lake park surpasses the other three parks located on the urban fringe, which have a smaller effective activity areas and a park trail density that is below the standard CDPP value. Overall, the improved comprehensive index more accurately describes park service capacity, especially the service capacity of physical activities. 




Figure 6. Comparison of $S_{j}$ values in terms of size-based data and comprehensive data.

\subsubsection{Variable Thresholds of Connection Values}

A fixed catchment is one of the major limitations of the traditional 2SFCA model [31], which uses the same maximum distance for the city parks' and community parks' catchment value $\left(d_{0}\right)$. In this study, we present variable thresholds that are modified using different cut-off values based on previous research on Chinese cities [35,36], online surveys, and local normative standards; these values represent variable maximum acceptable distances (or times) for the type of park and residents' travel modes. In total, there are eight different maximum values (three types of parks under three transportation modes, excluding driving to neighborhood parks).

\subsection{Contributions to the Literature}

This study attempted to contribute to the literature on environmental justice in terms of access to parks for different social groups. Previous studies have associated park accessibility with demographic groups to varying degrees, such as racial ethnic composition and socioeconomic status $[22,23,33,44,49,51,53-55]$. Our study adds to the current literature on disparities in park services by associating park accessibility with the heterogeneity of the built environment in residential communities. Open communities and gated communities are firstly distinguished to explore disparities in access to public parks with regard to "geographical justice". Some scholars indicate that people living in open communities tend to have lower incomes, less automobile ownership, less education, and inferior living environments than those in gated communities in Chinese cities [39]. Thus, residents living in open communities can be generally regarded as socioeconomically disadvantaged groups. The results of this study suggest that people living in open communities have lower mean values of park accessibility, indicating that socioeconomically disadvantaged groups have less opportunity to access public parks, which is in line with prior research [23,56-60].

\subsection{Policy Implications}

The findings from this research have important policy implications for urban green space planning. To target the specific areas lacking park services in the compact megacity of Nanjing, we evaluated the disparities in access to public parks at the community level. The community, as the smallest level and basic unit for census, is administered by a residential committee. Evaluating the ability to access parks from the perspective of the community is conducive to accurately identifying specific areas and assisting local governments in implementing optimization strategies efficiently [36]. In this case, we identified 484 communities with park accessibility scores of zero, which suggests that residents 
living in those areas cannot access any public parks by walking, bicycling, or driving within the acceptable time limit. Among these communities, 105 open communities were identified, accounting for $62.9 \%$ of the total open communities, and 167 gated communities without a "club park" were identified, accounting for $12.6 \%$ of the total gated communities. Residents living in these communities are the most vulnerable groups with regard to a lack of park services. Therefore, policy makers should prioritize them when establishing new parks or expanding existing parks. In addition, we also found 242 communities in which residents can visit parks by driving only. For these communities, more sidewalks and bike lanes are necessary to encourage residents to visit the public parks.

\subsection{Limitations}

Several limitations of this study should be acknowledged. First, supply capacity and attractiveness were assessed by focusing only on the physical presence of certain attributes of urban parks, such as effective activity areas, tree canopy coverage, and park trail density; certain complex ecosystem services indexes were ignored. However, our model can easily be modified to incorporate more objective indexes or account for other factors, such as the park diversity of species. Moreover, the weight of each of the factors can be adjusted. Second, although we considered the heterogeneity of the built environment in residential communities, the characteristics and preferences of the users were ignored. For example, people with disabilities need considerable park services, and teenagers may favor active sports such as soccer and tennis, whereas older people prefer walking on park trails and more passive entertainment [34]. Therefore, further research should focus on the corresponding relationship between the demand side and the supply side to develop more realistic models for public facilities. In addition, we overestimated the accessibility of gated communities, because the cul-de-sacs of a gated community cannot act as a "central point", thus reducing connectivity and increasing travel time. Third, geometric centroids used to represent the park may have underestimated its supply capacity and accessibility as a result of overlooking park entrances and the length of the open edge, especially in the case of larger scale parks. Fourth, we assumed that all residents have bicycles and cars and ignored individuals' actual activity travel patterns. Moreover, the bus travel mode was not considered because of the uncertainty of mixed travel modes (e.g., walking to bus stations) and the difficulty in obtaining bus station and route data, which may influence the findings to some extent.

\section{Conclusions}

Access to urban parks encourages physical activity and benefits public health. However, a major concern of social equity and environmental justice is whether urban green resources are equitably distributed in high-density urban core areas. This research aimed to (1) systematically analyze the concepts, influencing factors, and calculation models of park accessibility and propose the 2SFCA family of metrics as a relatively optimal method that considers the distance-decay effect, supply, and demand; (2) use the popular Gaussian-2SFCA model and improve the two core parameters $\left(S_{j}\right.$ and $\left.d_{0}\right)$ to realistically evaluate the accessibility of public parks; and (3) use Nanjing as a case by which to explore disparities in access to public parks in gated and open communities from the spatial heterogeneity perspective. Ultimately, our studies can assist in targeting shortage areas of park accessibility under different travel modes and identify specific communities with vulnerable groups lacking public park services, thereby helping city planners and policy makers to evaluate the justice of park distribution to ensure equity in park accessibility.

Author Contributions: Conceptualization, J.Z. and B.Z.; Formal analysis, J.Z. and Y.C.; Investigation, J.Z., B.Z. and W.W.; Methodology, J.Z.; Writing—original draft, J.Z.; Writing-review \& editing, J.Z.

Funding: This research was funded by China Scholarship Council, grant number (NO.201908320579).

Acknowledgments: The authors would like to thank Prof. Zhaowu Yu, Prof. Zhi Yue, Ms. Fangyu Zhou and Ms.Ganyu Feng for their assistance with reviewing or critiquing the drafts of this work.

Conflicts of Interest: The authors declare no conflict of interest. 


\section{References}

1. Hartig, T.; Mitchell, R.; de Vries, S.; Frumkin, H. Nature and Health. Annu. Rev. Public Health 2014, 35, 207-228. [CrossRef] [PubMed]

2. Li, H.N.; Chau, C.K.; Tang, S.K. Can surrounding greenery reduce noise annoyance at home? Sci. Total Environ. 2010, 408, 4376-4384. [CrossRef] [PubMed]

3. Nagendra, H.; Divya, G. Tree diversity, distribution, history and change in urban parks: Studies in Bangalore, India. Urban Ecosyst. 2011, 14, 211-223. [CrossRef]

4. Yu, Z.; Guo, X.; Jørgensen, G.; Vejre, H. How can urban green spaces be planned for climate adaptation in subtropical cities? Ecol. Indic. 2017, 82, 152-162. [CrossRef]

5. Coombes, E.; Andrew, P.J.; Melvyn, H. The relationship of physical activity and overweight to objectively measured green space accessibility and use. Soc. Sci. Med. 2010, 70, 816-822. [CrossRef]

6. Paquet, C.; Orschulok, T.; Coffee, N.; Howard, N.; Hugo, G.; Taylor, A.; Adams, R.; Daniel, M. Are accessibility and characteristics of public open spaces associated with a better cardiometabolic health? Landsc. Urban Plan. 2013, 118, 70-78. [CrossRef]

7. Sturm, R.; Cohen, D. Proximity to urban parks and mental health. J. Ment. Health Policy Econ. 2014, 17, $19-24$.

8. Ayala-Azcárraga, C.; Diaz, D.; Zambrano, L. Characteristics of urban parks and their relation to user well-being. Landsc. Urban Plan. 2019, 189, 27-35. [CrossRef]

9. Rigolon, A. A complex landscape of inequity in access to urban parks: A literature review. Landsc. Urban Plan. 2016, 153, 160-169. [CrossRef]

10. Wolch, J.R.; Byrne, J.A.; Newell, J.P. Urban green space, public health, and environmental justice: The challenge of making cities 'just green enough'. Landsc. Urban Plan. 2014, 125, 234-244. [CrossRef]

11. Lin, T.; Xia, J.; Robinson, T.P.; Goulias, K.G.; Church, R.L.; Olaru, D.; Tapin, J.; Han, R. Spatial analysis of access to and accessibility surrounding train stations: A case study of accessibility for the elderly in Perth, Western Australia. J. Transp. Geogr. 2014, 39, 111-120. [CrossRef]

12. Yang, S.; Liu, X.; Wu, Y.-J.; Woolschlager, J.; Coffin, S.L. Can freeway traffic volume information facilitate urban accessibility assessment? J. Transp. Geogr. 2015, 44, 65-75. [CrossRef]

13. Giles-Corti, B.; Melissa, H.B.; Matthew, K.; Catherine, C.; Kate, D.; Kevin, N.; Andrea, L.; Robert, J.D. Increasing walking: How important is distance to, attractiveness, and size of public open space? Am. J. Prev. Med. 2005, 28, 169-176. [CrossRef] [PubMed]

14. Grow, H.M.; Saelens, B.E.; Kerr, J.; Durant, N.H.; Norman, G.J.; Sallis, J.F. Where Are Youth Active? Roles of Proximity, Active Transport, and Built Environment. Med. Sci. Sports Exerc. 2008, 40, 2071-2079. [CrossRef]

15. Kaczynski, A.T.; Henderson, K.A. Environmental Correlates of Physical Activity: A Review of Evidence about Parks and Recreation. Leis. Sci. 2007, 29, 315-354. [CrossRef]

16. Talen, E. Neighborhoods as Service Providers: A Methodology for Evaluating Pedestrian Access. Environ. Plan. B Plan. Des. 2003, 30, 181-200. [CrossRef]

17. Katherine, B.V.M.P.H.; Andrew, T.K.P.D. Exploring the Distribution of Park Availability, Features, and Quality Across Kansas City, Missouri by Income and Race/Ethnicity: An Environmental Justice Investigation. Ann. Behav. Med. 2013, 45, S28-S38.

18. Nicholls, S.; Shafer, C.S. Measuring accessibility and equity in a local park system: The utility of geospatial technologies to park and recreation professionals. J. Park Recreat. Adm. 2001, 19, 102-124.

19. Potestio, M.L.; Alka, B.P.; Christopher, D.P.; Deborah, A.M.; Jacobson, R.D.; Lindsay, M. Is there an association between spatial access to parks/green space and childhood overweight/obesity in Calgary, Canada? Int. J. Behav. Nutr. Phys. Act. 2009, 6, 77. [CrossRef]

20. Richardson, E.; Jamie, P.; Richard, M.; Peter, D.; Simon, K. The association between green space and cause-specific mortality in urban New Zealand: An ecological analysis of green space utility. BMC Public Health 2010, 10, 1-14. [CrossRef]

21. Talen, E. Measuring the public realm: A preliminary assessment of the link between public space and sense of community. J. Archit. Plan. Res. 2000, 17, 344-360.

22. Oh, K.; Jeong, S. Assessing the spatial distribution of urban parks using GIS. Landsc. Urban Plan. 2007, 82, 25-32. [CrossRef]

23. Comber, A.; Chris, B.; Edmund, G. Using a GIS-based network analysis to determine urban greenspace accessibility for different ethnic and religious groups. Landsc. Urban Plan. 2008, 86, 103-114. [CrossRef] 
24. Moore, L.V.; Ana, V.D.R.; Kelly, R.E.; Aileen, P.M.; Shannon, J.B. Availability of Recreational Resources in minority and Low Socioeconomic Status Areas. Am. J. Prev. Med. 2008, 34, 16-22. [CrossRef]

25. Sister, C.; Jennifer, W.; John, W. Got green? addressing environmental justice in park provision. Geojournal 2010, 75, 229-248. [CrossRef]

26. Wu, C.; Ye, X.; Du, Q.; Luo, P. Spatial effects of accessibility to parks on housing prices in Shenzhen, China. Habitat Int. 2017, 63, 45-54. [CrossRef]

27. Luo, W.; Yi, Q. An enhanced two-step floating catchment area (E2SFCA) method for measuring spatial accessibility to primary care physicians. Health Place 2009, 15, 1100-1107. [CrossRef]

28. Wang, F.; Quan, T. Planning toward equal accessibility to services: A quadratic programming approach. Environ. Plan. B Plan. Des. 2013, 40, 195-212. [CrossRef]

29. Dai, D.; Wang, F. Geographic disparities in accessibility to food stores in southwest Mississippi. Environ. Plan. B Plan. Des. 2011, 38, 659-677. [CrossRef]

30. Dai, D. Black residential segregation, disparities in spatial access to health care facilities, and late-stage breast cancer diagnosis in metropolitan Detroit. Health Place 2010, 16, 1038-1052. [CrossRef]

31. Luo, W.; Wang, F. Measures of Spatial Accessibility to Health Care in a GIS Environment: Synthesis and a Case Study in the Chicago Region. Environ. Plan. B Plan. Des. 2003, 30, 865-884. [CrossRef]

32. Wang, F. Measurement, Optimization, and Impact of Health Care Accessibility: A Methodological Review. Ann. Assoc. Am. Geogr. 2012, 102, 1104-1112. [CrossRef] [PubMed]

33. Wei, F. Greener urbanization? Changing accessibility to parks in China. Landsc. Urban Plan. 2017, 157, 542-552. [CrossRef]

34. Dony, C.C.; Delmelle, E.M.; Delmelle, E.C. Re-conceptualizing accessibility to parks in multi-modal cities: A Variable-width Floating Catchment Area (VFCA) method. Landsc. Urban Plan. 2015, 143, 90-99. [CrossRef]

35. Xing, L.; Liu, Y.; Liu, X. Measuring spatial disparity in accessibility with a multi-mode method based on park green spaces classification in Wuhan, China. Appl. Geogr. 2018, 94, 251-261. [CrossRef]

36. Xu, M.; Xin, J.; Su, S.; Weng, M.; Cai, Z. Social inequalities of park accessibility in Shenzhen, China: The role of park quality, transport modes, and hierarchical socioeconomic characteristics. J. Transp. Geogr. 2017, 62, 38-50. [CrossRef]

37. Rigolon, A.; Flohr, T. Access to Parks for Youth as an Environmental Justice Issue: Access Inequalities and Possible Solutions. Buildings 2014, 4, 69-94. [CrossRef]

38. Miao, P. Deserted Streets in a Jammed Town: The Gated Community in Chinese Cities and Its Solution. J. Urban Des. 2003, 8, 45-66. [CrossRef]

39. Dong, W.; Cao, X.; Wu, X.; Dong, Y. Examining pedestrian satisfaction in gated and open communities: An integration of gradient boosting decision trees and impact-asymmetry analysis. Landsc. Urban Plan. 2019, 185, 246-257. [CrossRef]

40. Fuller, R.A.; Gaston, K.J. The scaling of green space coverage in European cities. Biol. Lett. 2009, 5, 352. [CrossRef]

41. Wu, Q.; Cheng, J.; Chen, G.; Hammel, D.J.; Wu, X. Socio-spatial differentiation and residential segregation in the Chinese city based on the 2000 community-level census data: A case study of the inner city of Nanjing. Cities 2014, 39, 109-119. [CrossRef]

42. GeoffreyDutton. Improving locational specificity of map data-A multi-resolution, metadata-driven approach and notation. Int. J. Geogr. Inf. Syst. 1996, 10, 253-268.

43. Xiao, Y.; Li, Z.; Webster, C. Estimating the mediating effect of privately-supplied green space on the relationship between urban public green space and property value: Evidence from Shanghai, China. Land Use Policy 2016, 54, 439-447. [CrossRef]

44. Dai, D. Racial/ethnic and socioeconomic disparities in urban green space accessibility: Where to intervene? Landsc. Urban Plan. 2011, 102, 234-244. [CrossRef]

45. Li, L.; Du, Q.; Ren, F.; Ma, X. Assessing spatial accessibility to hierarchical urban parks by multi-types of travel distance in Shenzhen, China. Int. J. Environ. Res. Public Health 2019, 16, 1038. [CrossRef] [PubMed]

46. Evenson, K.R.; Wen, F.; Hillier, A.M.Y.; Cohen, D.A. Assessing the Contribution of Parks to Physical Activity Using Global Positioning System and Accelerometry. Med. Sci. Sports Exerc. 2013, 45, 1981-1987. [CrossRef]

47. Anderson, C.; Jackson, K.; Egger, S.; Chapman, K.; Rock, V. Shade in urban playgrounds in Sydney and inequities in availability for those living in lower socioeconomic areas. Aust. N. Z. J. Public Health 2014, 38, 49-53. [CrossRef] 
48. Ma, F.; He, J.; Ma, J.; Xia, S. Evaluation of urban green transportation planning based on central point triangle whiten weight function and entropy-AHP. Transp. Res. Procedia 2017, 25, 3638-3648. [CrossRef]

49. Boone, C.G.; Buckley, G.L.; Grove, J.M.; Sister, C. Parks and People: An Environmental Justice Inquiry in Baltimore, Maryland. Ann. Assoc. Am. Geogr. 2009, 99, 767-787. [CrossRef]

50. Shiode, N.; Shino, S. Street-level Spatial Interpolation Using Network-based IDW and Ordinary Kriging. Trans. Gis 2011, 15, 457-477. [CrossRef]

51. Lee, G.; Hong, I. Measuring spatial accessibility in the context of spatial disparity between demand and supply of urban park service. Landsc. Urban Plan. 2013, 119, 85-90. [CrossRef]

52. Pham, T.-T.-H.; Labbé, D.; Lachapelle, U.; Pelletier, É. Perception of park access and park use amongst youth in Hanoi: Howcultural and local context matters. Landsc. Urban Plan. 2019, 189, 165-169. [CrossRef]

53. Ibes, D.C.J.L.; Planning, U. A multi-dimensional classification and equity analysis of an urban park system: A novel methodology and case study application. Landsc. Urban Plan. 2015, 137, 122-137. [CrossRef]

54. Koohsari, M.J. Access to public open space: Is distribution equitable across different socio-economic areas. J. Urban Environ. Eng. 2011, 5, 67-72. [CrossRef]

55. Tan, P.Y.; Samsudin, R. Effects of spatial scale on assessment of spatial equity of urban park provision. Landsc. Urban Plan. 2017, 158, 139-154. [CrossRef]

56. Estabrooks, P.A.; Lee, R.E.; Gyurcsik, N.C. Resources for physical activity participation: Does availability and accessibility differ by neighborhood socioeconomic status? Ann. Behav. Med. 2003, 25, 100-104. [CrossRef]

57. Gordon-Larsen, P.; Nelson, M.C.; Page, P.; Popkin, B.M. Inequality in the built environment underlies key health disparities in physical activity and obesity. Pediatrics 2006, 117, 417-424. [CrossRef]

58. Harris, C.D.; Paul, P.; Zhang, X.; Fulton, J.E. Park access among school-age youth in the United States. J. Phys. Act. Health 2015, 12, S94-S101. [CrossRef]

59. Taylor, W.C.; Floyd, M.F.; Whitt-Glover, M.C.; Brooks, J. Environmental justice: A framework for collaboration between the public health and parks and recreation fields to study disparities in physical activity. J. Phys. Act. Health 2007, 4, S50-S63. [CrossRef]

60. Gobster, P.H. Managing urban parks for a racially and ethnically diverse clientele. Leis. Sci. 2002, 24, 143-159. [CrossRef]

(C) 2019 by the authors. Licensee MDPI, Basel, Switzerland. This article is an open access article distributed under the terms and conditions of the Creative Commons Attribution (CC BY) license (http://creativecommons.org/licenses/by/4.0/). 